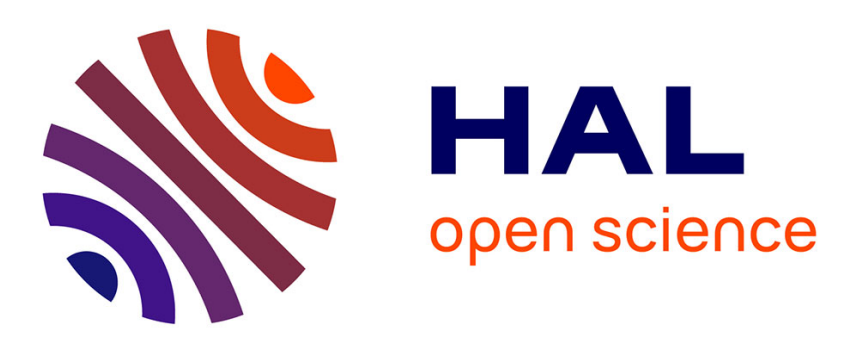

\title{
A new generic problem formulation dedicated to electrified railway systems
}

Boris Desjouis, Ghislain Remy, Florence Ossart, Claude Marchand, Jean Bigeon, Etienne Sourdille

\section{- To cite this version:}

Boris Desjouis, Ghislain Remy, Florence Ossart, Claude Marchand, Jean Bigeon, et al.. A new generic problem formulation dedicated to electrified railway systems. ESARS 2015, Mar 2015, Aachen, Germany. 10.1109/ESARS.2015.7101437 . hal-01241090

\section{HAL Id: hal-01241090 \\ https://hal.science/hal-01241090}

Submitted on 9 Dec 2015

HAL is a multi-disciplinary open access archive for the deposit and dissemination of scientific research documents, whether they are published or not. The documents may come from teaching and research institutions in France or abroad, or from public or private research centers.
L'archive ouverte pluridisciplinaire HAL, est destinée au dépôt et à la diffusion de documents scientifiques de niveau recherche, publiés ou non, émanant des établissements d'enseignement et de recherche français ou étrangers, des laboratoires publics ou privés. 


\title{
A new generic problem formulation dedicated to electrified railway systems
}

\author{
Boris Desjouis ${ }^{1,2,3}$, Ghislain Remy ${ }^{1}$, Florence Ossart ${ }^{1}$, Claude Marchand ${ }^{1}$, Jean Bigeon ${ }^{2}$, Etienne Sourdille ${ }^{3}$ \\ ${ }^{1}$ GEEPS - CNRS UMR 8507 - CentraleSupélec - UPSud - Sorbonne Université UPMC; 91192 Gif sur Yvette - France \\ ${ }^{2}$ G-SCOP - CNRS UMR 5272; Grenoble INP-UJF; 38000 Grenoble - France \\ ${ }^{3}$ SNCF, Direction de l'ingenierie, 6 avenue François Mitterrand, 95574 La Plaine St-Denis
}

\begin{abstract}
In this paper, a new generic problem formulation dedicated to railway electrification systems is proposed. This formulation meets the needs for evolutivity of modern simulation tools by using meta-models for the railway network components. This approach has been applied to developp a new generalpurpose electrified railway simulator. As an example, a DC electrification system has been simulated and the results compared to those of a classical simulator for validation purpose. A comparison of different resolution algorithms is also presented as a result of the possibilities offered by the new simulator.
\end{abstract}

Keywords—simulation; modeling; railway application.

\section{INTRODUCTION}

The growth of traffic or the construction of a new electrified railway require a sizing study for power supply facilities in order to meet standard needs and expected performance. This type of study is conducted using railway simulators based on assumptions whose outcomes serve as evidence for proposals to size or reinforce the power supply system. Several simulators of this type are now available [1-4], but they all face the same limitations. The first one is the lack of generality: each simulator is dedicated to a specific electrification system. The second challenge deals with evolutivity: new types of components, such as power storage systems [3] [5], are more and more implemented in existing electrification systems, and must be accounted for in simulation. Last, an emerging issue regards the optimal design of the railway network and its residual development capabilities. Powerful optimization methods are now available, but they require fast and robust models. The purpose of the work presented hereafter is to build a new railway simulator meeting those requirements: flexibility, robustness and evolution capability are obtained by using the concept of meta-models.

The paper is organized as follows: the principles of railway modeling are recalled, then the constitution of the meta-model is proposed and the principles of its implementation in a railway simulator are discussed. A comparison between different solving algorithms available for this type of simulator is performed. Finally, the results of the new simulator and those of a reference simulator are compared in the case of a DC system.

\section{PRINCIPLES OF RAILWAY POWER SUPPLY MODELING}

A railway electrification system is the set of facilities used to supply electrical power to the trains: feeding sub-station, transformers, rectifiers, catenaries, motors ... The trains are supplied with high voltage alternative- or direct-current by a third rail or catenary and the return current flows either through the rails of the track or a fourth dedicated rail. The electrical network is described using lines, tracks and kilometer points, which allow locating the different components relatively to each other.

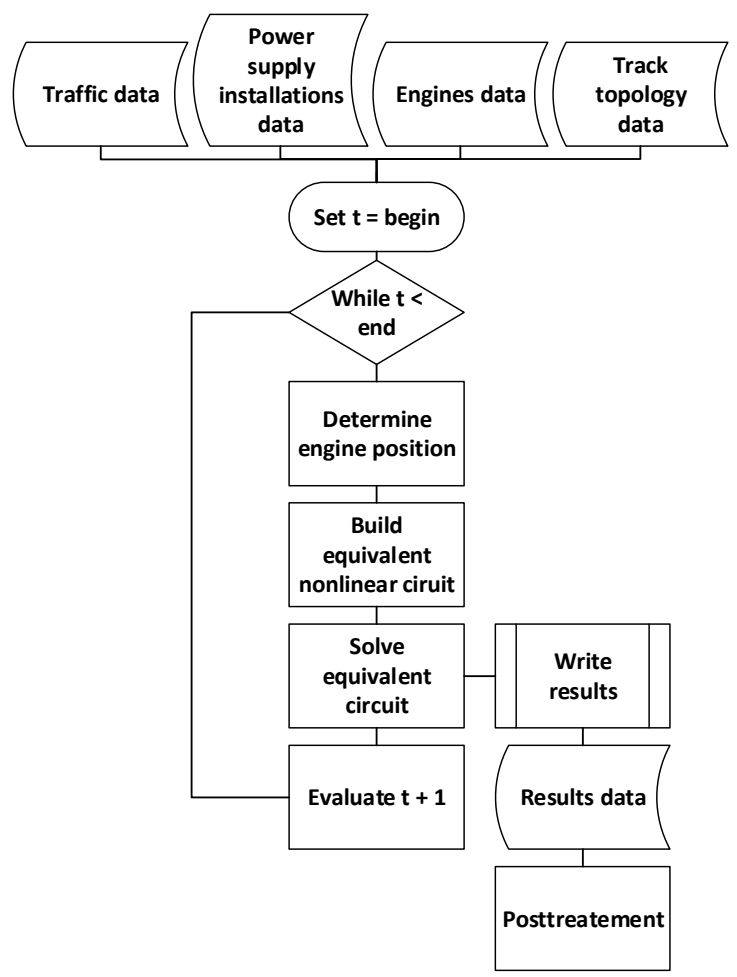

Fig. 1. Block diagramm of railway power supply simulator.

The main principles of railway simulation are well defined [1] [2] [4] [6]. The goal is to assess the capability of a given power supply network to provide the trains with the electrical power they need to fulfill their mission at the desired performance level. The spatial characterization of the trains' missions allows to determine what power the network must 
provide. Most vehicles use regulation devices, in order to adapt the power actually drawn to what is available on the network. This leads to a non-linear behavior of the system and forbids the use of power flow techniques [2] [6] to model it. Hence, circuit-style methods are required. All available simulators proceed in an equivalent fashion (Fig. 1): they simulate the dynamic of traffic flows by generating a nonlinear electrical circuit at each step of time, and then calculate all of the electrical values within the circuit.

The existence of many electrification systems [7] has led to the creation of different dedicated simulators, each one using models and problem-solving methods specific to the considered system [1] [2] [4] [6]. Analyzing these various methods did not allow us to identify the one that would allow a generic, expandable representation of the modeled system, which is why we have developed a new methodology based on meta-models, and built a general-purpose, expandable electric railway simulator.

\section{PROPOSED GENERIC PROBLEM FORMULATION}

The power supply system consists of so-called "longitudinal" components (rails, catenaries ...) and "parallel" ones (substations, transformers, train ...). The usual way of modeling the railway electrical circuit is to build up a bus admittance matrix, defined by the longitudinal components of the line and stamped with predefined models of the parallel components [1]. The different components are represented by semi-analytical models, whose parameters include position information (line, track, position on the line if applicable). The structure of the stamp that a component model must fulfill depends on the considered electrification system. A drawback of this approach when applied to railway is that the bus may vary a lot, as its structure is defined by whatever installations are present in the system. Additionally, the network is constantly being reconfigured according to the trains' positions. Furthermore, the very notion of a bus complicates the formulation of the circuit problem when the railway network consists of multiple lines and tracks. The use of graph theory allows for clever solutions to problems related to network reconfiguration [8] [9], but imposes conditions on the depiction of the elements in the graph. For example, a catenary will necessary appear as an edge, while a substation will appear as a vertex. This reduces the evolving capability of the problem formulation. As our goal is to depict and simulate various railway systems in a generic way, we have chosen a different approach and implemented a dynamic graph.

\section{A. Reconstructing a parallel/serial multi-graph}

Formulating a generic circuit problem requires to be able to use component models that can be defined afterward, at the time when the simulation is carried out. We have therefore designed a meta-model of railway network component relying on a set of predefined properties. Given the positions of the elements within the network (lines and tracks it belongs to, kilometer point), it is possible to build the graph of relationships between the elements. The predefined properties of the meta-model are:
- $\quad$ Type of component (discrete or continuous)

- Transversality

- Desired mutual effect

- List of desired outside connections

- List of internal connections

Using these properties, an element may form one or more arcs on the graph, generate one or more vertices, or even be part of the structure of those vertices. The potential connections do not need to be specified in advance: if two elements positioned at the same place want to make the same connection defined afterward, then they are both part of the creation of a vertex. Presence in a single location is defined spatially by the lines, the tracks that make them up, and the kilometer points. It is also defined electrically according to the property "discrete" or "continuous", which indicates the element's ability to form a single vertex regardless its spatial position, or one vertex on each of the spatial positions, respectively. The element property "transversality" indicates its ability to form different vertices on each track. For example, a single sub-station connected to several lines, each of them feeding a track at a different kilometer point, will constitute a single catenary vertex on the graph. Fig. 2 gives an example of algorithm which interpretes a component's properties. All algorithms developed for each element are called when that element is assigned to a new position. In response, they modify only part of the graph. This local reconstruction reduces computation time. The graph is initially constructed by all the elements of the power supply network. As a large railway network consist of many elements, this initial formulation may be rather long, but the successive reconstructions, performed at the local level as the trains are moving, are fast.

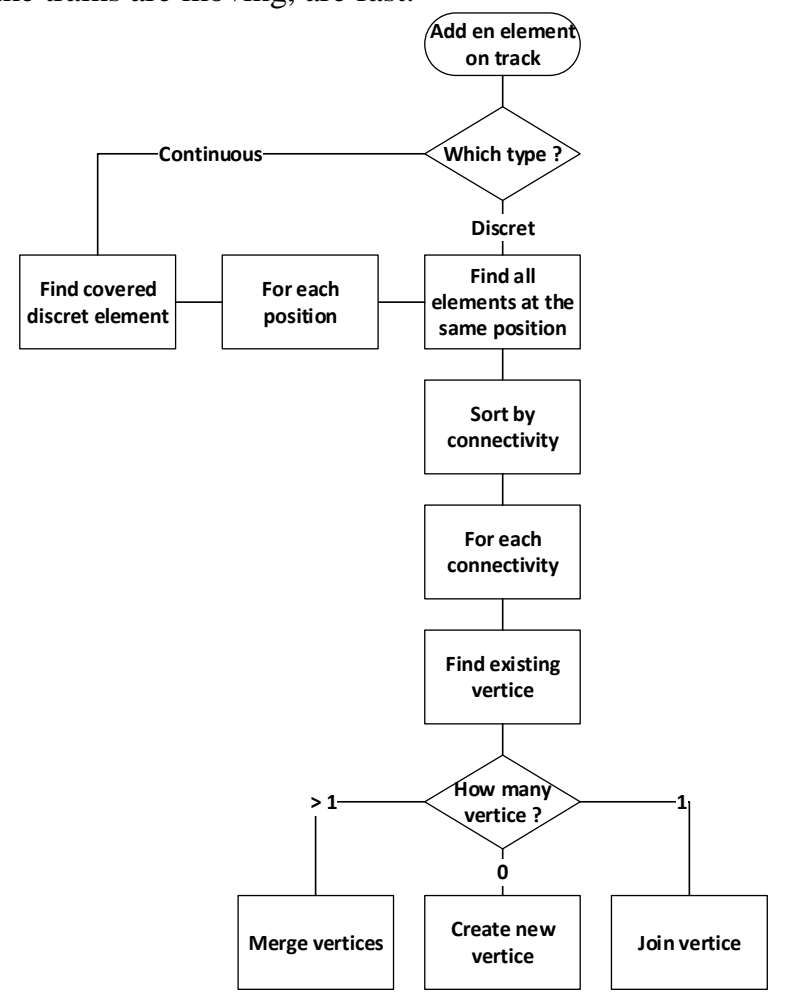

Fig. 2. Portion of an algorithm developed to modify the multigraph when a new element is associated to a new position. 


\section{B. Graph coloring and optimal route}

The graph formed by defining relationships between the elements by correlating their properties does not directly produce a solvable circuit graph. This is because the use of the graph as-is may lead to the creation of a singular matrix when the problem is formulated. This would happen if a vertex were formed because two elements in the same position share the same connectivity while being associated with the vertex that has the circuit's reference node. To handle this problem, we use the fact that the elements can be directly assigned to the vertices that they form in the graph, so that each vertice can be colored according to the element model. We therefore have added to the meta-model a graph-coloring method, which works as follows. The elements that define the reference nodes assign the indicator $\alpha$ to the corresponding vertices; the elements that use a source of voltage assign the indicator $\beta$, and the elements that use a source of current assign an indicator $\delta$. The indicator $\alpha$ takes precedence over $\beta$ and $\delta$. Next, a depth-first search within the graph starts from the reference node and retains only the sub-graphs in which the indicators $\beta$ or $\delta$ appear at least once.

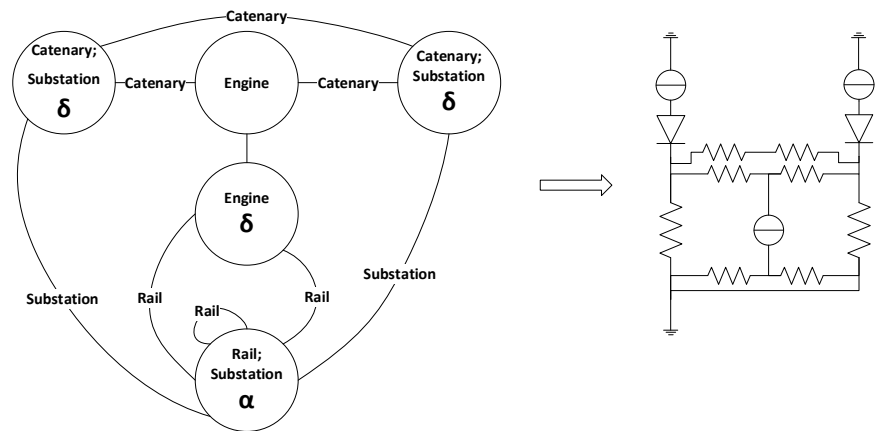

Fig. 3. Dynamic building of the graph and circuit formulation for 2 earthed substations suppling 2 tracks. Each track consists of a catenary and a rail. One engine is moving on track 1.

\section{Problem formulation by the components}

We have created a set of algorithms that make it possible to build the graph representing the solvable portion of the circuit given a set of predefined general properties of the elements. There are several analysis methods for formulating a circuit problem, including mesh analysis, nodal analysis, or the use of a modified nodal analysis [6]. Given its ease at locating the circuit's nodes and the options for representation, modified nodal analysis with linked sources of current and voltage was a natural choice for us [10]. Next we build the problem in the form of a matrix. The use of modified nodal analysis introduces constraints on potentials that increase the matrix size. An additional property of the meta-model is used to define this mechanism. We therefore establish a pre-assembly phase, at the end of which the problem's matrix structure is defined. As each vertex and arc in the graph is formed by the elements (Fig. 3), those elements possess the nodes which they form in the circuit, and ultimately their link indices in the problem's structure. The element models may then explicitly formulate the non-linear problem in the matrix form:

$$
\text { A. } x-b(x)=0
$$

where $A$ is the admittance matrix plus the distribution of constraints on the potentials, $x$ is the vector of the potentials concatenated with the current of the constraints and $b(x)$ is the vector of the injected currents concatenated with the potentials' values. Each element locally participates in formulating the problem through its link indices. This means that it is represented by increasing or decreasing the values of the quantities located at the indices in the matrices and vectors (admittance or current, whichever is present). As the problem is non-linear, the element models are needed to calculate the second member and the Jacobian matrix. The element metamodel is therefore completed by two methods used for processing non-linear elements:

\section{- Evaluation of the second member}

- Evaluation of the Jacobian

Just as with the formulation, these evaluations are performed at the model's local level, and the models express their nonlinearity by increasing or decreasing the values of the quantities located at the link indices. It should be noted that the non-linearity of certain component models affect the problem's topology itself. This is true, to give on example, for linear modeling using diode pieces for substations. Taking this ideal behavior into account requires reconfiguring the network in order to eliminate the equivalent admittance of turned-off diodes. To handle these topological changes, a convergence loop testing the state of the diodes has been added.

\section{SOLVING ALGORITHMS PERFORMANCES}

The proposed method leads to the same type of evolutive circuit problems than other simulators: at each step of time, one has to solve a non linear problem, characterized by a sparse and symmetrical matrix [2] [6]. We can benefit from their experience in how to numerically handle this type of problem, but we must also anticipate the fact that new components are to be integrated in our simulator, and that their behavior may lead to numerical difficulties not encountered at the time being. For this reason, we have decided to use a powerful parallel computing library, Petsc [11], which provides us with a wide range of solving methods. In this section, we analyze the performances of some of them.

Railway network power supply simulations include the prediction of the train displacement. Hence, the state of the network calculated at a given time depends on the results calculated at the past time (Fig. 1). If convergence fails at a given time, none of the results obtained after can be trusted. For this reason, the first criterion when choosing a solver is robustness: the solving method must be able to converge for every problem formulated during the simulation. The second criterion is the computing time.

In order to determine which algorithms are the most efficient to solve our problem, we have tested and compared a number of them: linear and non linear solvers, matrix ordering methods, and preconditionners. The test case is described in section $\mathrm{V}$. The simulations were performed on a laptop with a processor Intel® Core TM i7-3840QM clocked at $2.80 \mathrm{GHz}$ 
with 32 GB RAM. Over hundred combinations of algorithms were tested, but only the most interesting results are presented here. Fig. 4 to 6 report the computation time for different algorithm combinations. The average number of iterations required by the linear solver and its standard deviation are also given. The latest figure is interpreted as a measure of robustness: a small standard deviation indicates that the linear solver behaves in a similar way whatever the system to solve.

\begin{tabular}{|c|c|c|c|c|}
\hline Matrix ordering & Linear solver & $\begin{array}{c}\text { Computation } \\
\text { time in s }\end{array}$ & $\begin{array}{c}\text { Average of } \\
\text { iteration } \\
\text { number } \\
\text { required by } \\
\text { linear solver }\end{array}$ & $\begin{array}{c}\text { Standard deviation of } \\
\text { iteration number } \\
\text { required by linear } \\
\text { solver }\end{array}$ \\
\hline $\begin{array}{c}\text { Nested } \\
\text { Dissection }\end{array}$ & GMRES & 58 & 342 & 61 \\
\hline $\begin{array}{c}\text { Nested } \\
\text { Dissection }\end{array}$ & PCG & 20 & 95 & 9 \\
\hline $\begin{array}{c}\text { Natural Ordering } \\
\text { One-way } \\
\text { Dissection }\end{array}$ & GMRES & 20 & 17 & 6 \\
\hline $\begin{array}{c}\text { Quotient } \\
\text { Minimum Degree }\end{array}$ & GMRES & 18 & 17 & 4 \\
\hline $\begin{array}{c}\text { Reverse Cuthill- } \\
\text { McKee }\end{array}$ & GMRES & 15 & 17 & 2 \\
\hline $\begin{array}{c}\text { Reverse Cuthill- } \\
\text { McKee }\end{array}$ & PCG & 16 & 17 & 2 \\
\hline
\end{tabular}

Fig. 4. Influence of matrix ordering on GMRES and PCG linear solver performances. The non linearity is handled using the trust region algorithm.

The matrix ordering was found to strongly influence the linear solver efficiency, some methods being more sensitive than others. For example, Fig. 4 shows that the PCG method is less affected than the GMRES one, but that the reverse Cuthill-McKee ordering method allows to achieve similar very good performances in all cases.

\begin{tabular}{|c|c|c|c|c|c|}
\hline Linear solver & Type & Preconditioner & $\begin{array}{c}\text { Computation } \\
\text { time in s }\end{array}$ & $\begin{array}{c}\text { Average of } \\
\text { iteration } \\
\text { number } \\
\text { required by } \\
\text { linear solver }\end{array}$ & $\begin{array}{c}\text { Standard } \\
\text { deviation of } \\
\text { iteration } \\
\text { number } \\
\text { required by } \\
\text { linear solver }\end{array}$ \\
\hline PCG & iterative & none & 29 & 262 & 37 \\
\hline PCG & iterative & $\begin{array}{c}\text { incomplete } \\
\text { Cholesky } \\
\text { factorization }\end{array}$ & 16 & 17 & 2 \\
\hline PCG & iterative & $\begin{array}{c}\text { incomplete LU } \\
\text { factorization }\end{array}$ & 16 & 17 & 2 \\
\hline PCG & iterative & diagonal scaling & 26 & 198 & 28 \\
\hline GMRES & iterative & none & 507 & 3719 & 535 \\
\hline GMRES & iterative & $\begin{array}{c}\text { incomplete } \\
\text { Cholesky }\end{array}$ & 15 & 17 & 2 \\
\hline GMRES & iterative & $\begin{array}{c}\text { incomplete LU } \\
\text { factorization }\end{array}$ & 15 & 17 & 2 \\
\hline GMRES & iterative & diagonal scaling & failure & 1206 & 1385 \\
\hline LU factorization & direct & none & 13 & 1 & 0 \\
\hline $\begin{array}{c}\text { Cholesky } \\
\text { factorization }\end{array}$ & direct & none & 14 & 1 & 0 \\
\hline
\end{tabular}

Fig. 5. Performances of different linear solver algorithms. The reverse Cuthill-McKee ordering and the trust region algorithm are used.
Fig. 5 focuses on the linear solver performances and show that direct methods are the fastest ones. However, iterative methods with a good preconditioner are scarcely less effective. One must also consider that the GMRES and PCG methods are easy to parallelize, but since the test was performed on a single processor machine, the efficiency gain could not be assessed.

\begin{tabular}{|c|c|c|c|c|}
\hline Nonlinear solver & Numbers of failures & $\begin{array}{c}\text { Computation } \\
\text { time in s }\end{array}$ & $\begin{array}{c}\text { Average of iteration } \\
\text { number required by } \\
\text { nonlinear solver }\end{array}$ & $\begin{array}{c}\text { Standard } \\
\text { deviation of } \\
\text { iteration number } \\
\text { required by } \\
\text { nonlinear solver }\end{array}$ \\
\hline Trust region & 0 & 14 & 7 & 3 \\
\hline $\begin{array}{c}\text { Basic newton's } \\
\text { method }\end{array}$ & 0 & 13 & 7 & 3 \\
\hline $\begin{array}{c}\text { Secant search in } \\
\text { the L2 norm of the } \\
\text { function }\end{array}$ & 0 & 13 & 6 & 2 \\
\hline $\begin{array}{c}\text { Critical point line } \\
\text { search }\end{array}$ & 0 & 13 & 6 & 3 \\
\hline $\begin{array}{c}\text { Backtracking line } \\
\text { search }\end{array}$ & 6 & 13 & 7 & 2 \\
\hline
\end{tabular}

Fig. 6. Performances of different nonlinear methods, coupled with LU factorization linear solvers.

Fig. 6 shows that all the nonlinear methods we have tested are equivalent, but the backtracking line search method sometime fails to converge and should be avoided.

This comparison of different available methods corroborates the conclusions found in literature [2] [4]. It shows that several choices with good performances are possible and one can think that finding an efficient combination of method will not be an issue when considering new models.

\section{ApPlicAtion to A TEST CASE}

\section{A. Description of the test case}

The proposed approach has been tested in the case of a direct-current network. The components used in this type of power supply have been modeled in the context of the metamodel described in section III. These components are:

- $\quad$ Sub-station with diode

- Catenary

- Rail

- Rolling stock

- Track paralleling hut

- Cross bond

- $\quad$ Line intersections

A test case involving a two-track line $50 \mathrm{~km}$ long with variable topography was simulated. Eight sub-stations supply the traffic, consisting of six trains: four high-speed, one suburban and one freight train. This test case was the one used to evaluate the solving algorithms in section IV. Fig. 7 shows an example of results. The same case was also studied in outage conditions, and Fig. 8 shows results when five substations are out of order. 

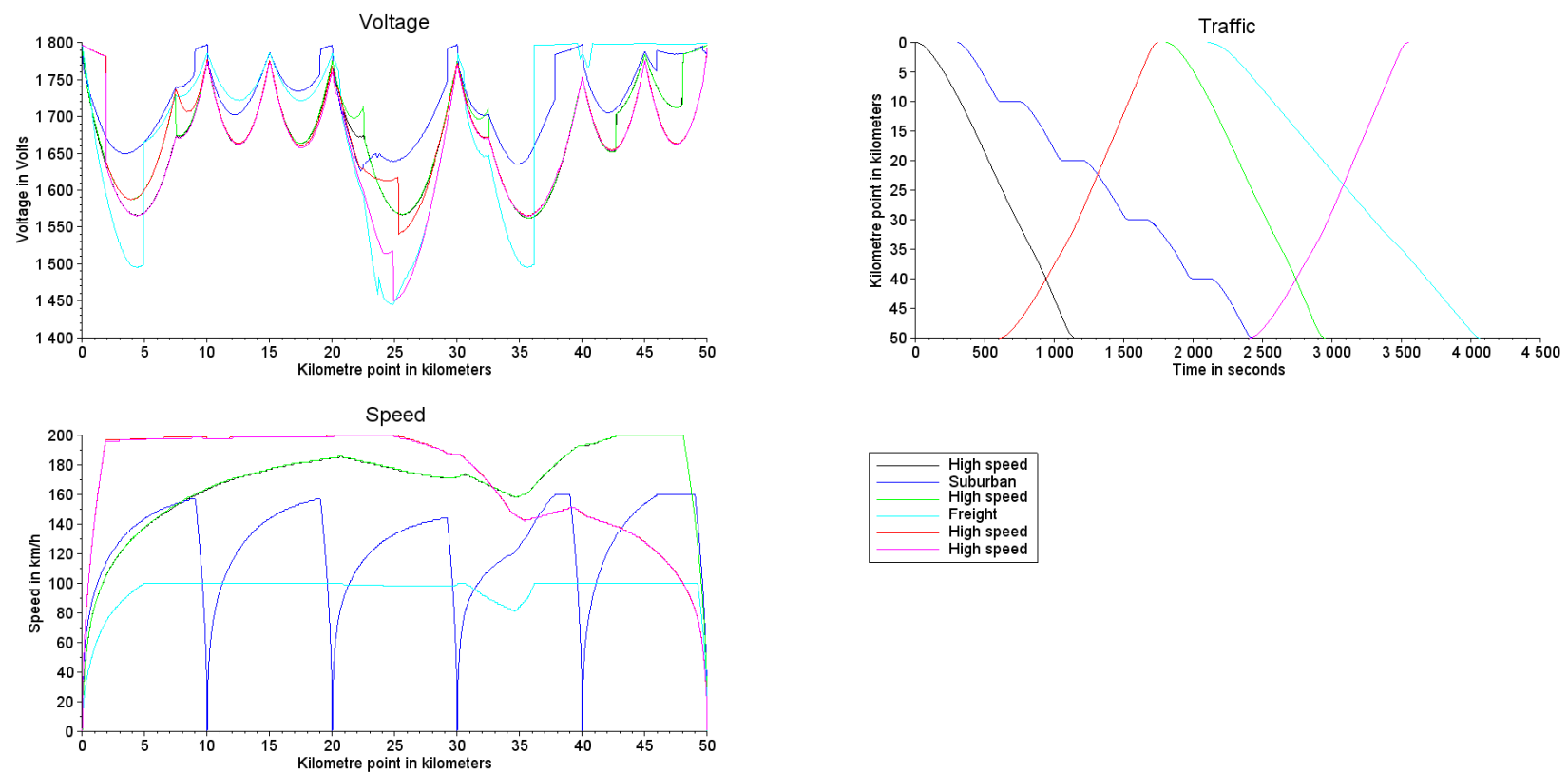

Fig. 7. Simulation results in nominal case : line voltage, traffic graph, dynamic of trains.
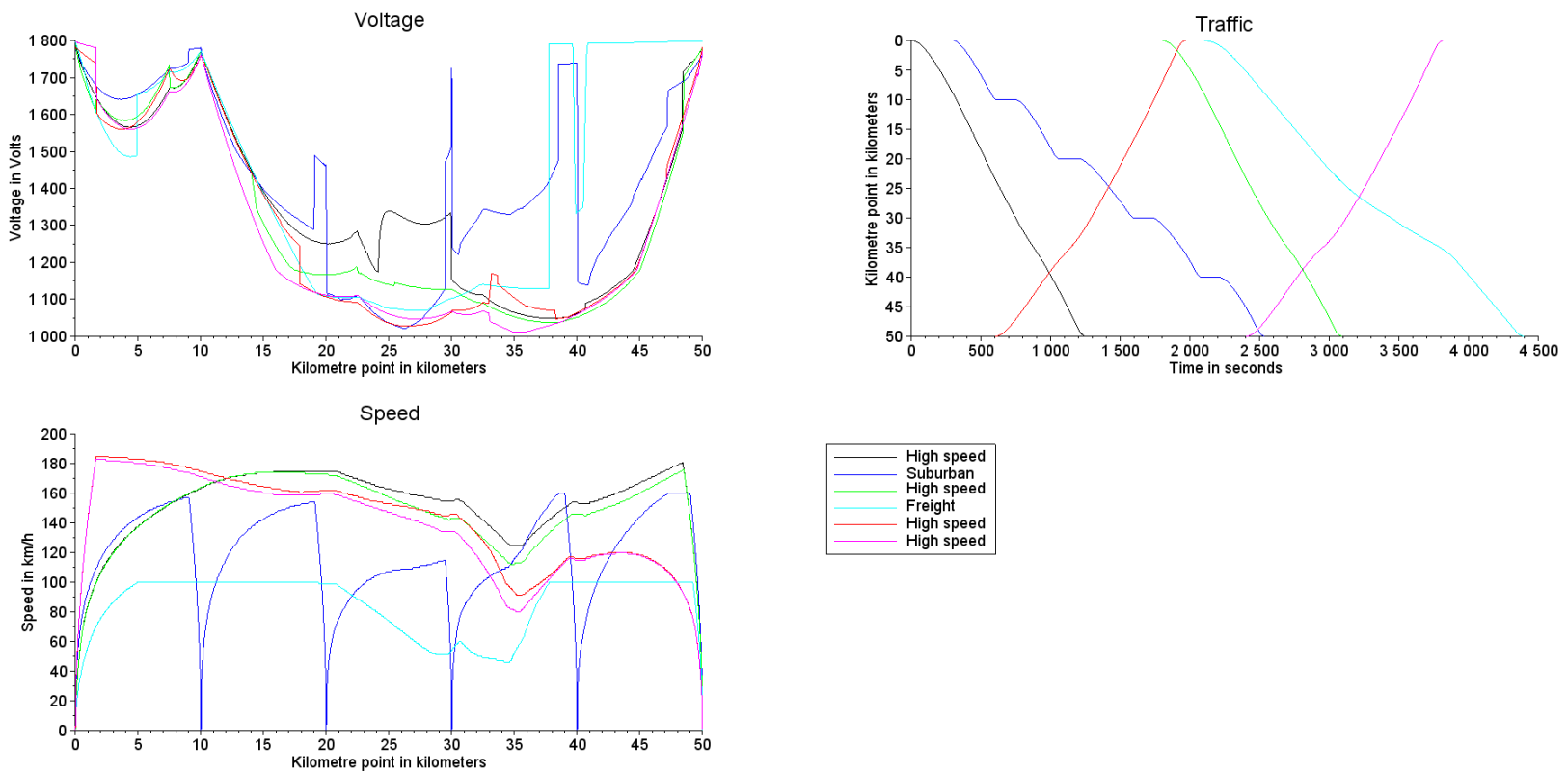

Fig. 8. Simulation results in outage case : line voltage, traffic graph, dynamic of trains.

\section{B. Comparison with a standard simulator}

The results calculated with the new simulator are compared to those obtained with the standard tool ESMERALDA [12] in Fig. 9 and 10 and a good agreement is observed.

Fig. 9 shows the relative difference between the speed and voltage calculated by both simulators, in terms of maximum instantaneous discrepancy, average discrepancy over the whole simulation and standard deviation. The total travel time of the different trains is also reported and found to be very close for both simulators. The numerical implementation of the railway network model is different in both simulators, so that their results cannot be exactly the same. Some punctual discrepancies are observed, which may be rather important for outage conditions, but the average relative difference over the whole simulation is always less than 3\%. This indicates that both simulators predict the same overall dynamic evolution of the system. 


\begin{tabular}{|c|c|c|c|c|c|c|c|c|}
\hline \multirow{3}{*}{$\begin{array}{l}\stackrel{\Xi}{\Xi} \\
\stackrel{\Xi}{\Xi} \\
0\end{array}$} & \multirow{3}{*}{ 苞 } & \multicolumn{6}{|c|}{$\begin{array}{l}\text { Relative difference between ESMERALDA and the new } \\
\text { simulator for instantaneous values in time in } \%\end{array}$} & \multirow{3}{*}{ 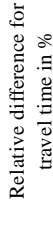 } \\
\hline & & \multicolumn{3}{|c|}{ Speed } & \multicolumn{3}{|c|}{ Voltage level } & \\
\hline & & 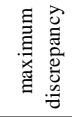 & 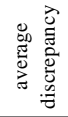 & 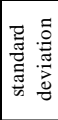 & 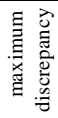 & 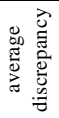 & 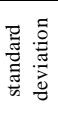 & \\
\hline \multirow{6}{*}{$\begin{array}{l}\text { 总 } \\
\text { : }\end{array}$} & 1.00 & 6.66 & 0.09 & 0.12 & 3.10 & 0.29 & 0.21 & 0.01 \\
\hline & 2.00 & 4.05 & 0.10 & 0.12 & 7.94 & 0.46 & 0.65 & 0.03 \\
\hline & 3.00 & 1.64 & 0.20 & 0.16 & 4.25 & 0.64 & 0.77 & 0.15 \\
\hline & 4.00 & 4.03 & 0.08 & 0.12 & 6.17 & 0.27 & 0.26 & 0.04 \\
\hline & 5.00 & 3.75 & 0.18 & 0.40 & 3.57 & 0.10 & 0.17 & 0.13 \\
\hline & 6.00 & 1.37 & 0.05 & 0.14 & 11.71 & 0.16 & 0.33 & 0.00 \\
\hline \multirow{6}{*}{ 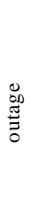 } & 1.00 & 11.61 & 2.64 & 3.26 & 21.72 & 3.35 & 5.26 & 2.09 \\
\hline & 2.00 & 6.26 & 1.57 & 1.56 & 11.82 & 1.41 & 1.73 & 1.09 \\
\hline & 3.00 & 4.19 & 0.37 & 0.20 & 11.70 & 0.78 & 1.12 & 0.28 \\
\hline & 4.00 & 3.06 & 0.20 & 0.20 & 7.83 & 0.30 & 0.38 & 0.03 \\
\hline & 5.00 & 14.52 & 0.89 & 1.71 & 27.20 & 1.45 & 2.44 & 0.30 \\
\hline & 6.00 & 2.05 & 0.15 & 0.29 & 35.45 & 0.18 & 0.91 & 0.01 \\
\hline
\end{tabular}

Fig. 9. Comparative table of dynamic evolution of speed and voltage level for the six trains.

Once that it has been checked that the global dynamics of the train are similar for both simulators, we can expect similar results at the level of the substations. For this reason, we restrain the analysis to the maximum mean power supplied by the different substations. Fig. 10 reports the results calculated by both simulators. The "1 min" (resp. "60 min") column corresponds to a mean value calculated over a 1 minute (resp. $60 \mathrm{~min}$ ) sliding time interval. The results are very close with a relative difference always less than $2 \%$.

\begin{tabular}{|c|c|c|c|c|c|c|c|c|}
\hline \multirow{3}{*}{ 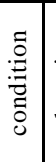 } & \multirow{3}{*}{ 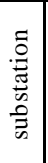 } & \multirow{3}{*}{ 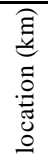 } & \multicolumn{4}{|c|}{$\begin{array}{c}\text { Maximum of moving average of } \\
\text { power supply in } \mathrm{kW}\end{array}$} & \multirow{2}{*}{\multicolumn{2}{|c|}{$\begin{array}{c}\text { Relative } \\
\text { difference in } \\
\%\end{array}$}} \\
\hline & & & \multicolumn{2}{|c|}{ New simulator } & \multicolumn{2}{|c|}{ ESMERALDA } & & \\
\hline & & & $1 \mathrm{~min}$ & $60 \mathrm{~min}$ & $1 \mathrm{~min}$ & $60 \mathrm{~min}$ & $1 \mathrm{~min}$ & $60 \mathrm{~min}$ \\
\hline \multirow{8}{*}{$=$} & 1 & 0 & 4492.69 & 1796.21 & 4486.18 & 1795.62 & 0.15 & 0.03 \\
\hline & 2 & 10 & 3855.13 & 1683.52 & 3854.19 & 1682.95 & 0.02 & 0.03 \\
\hline & 3 & 15 & 3462.71 & 1259.59 & $\mid 3463.54$ & 1260.05 & 0.02 & 0.04 \\
\hline & 4 & 20 & 5277.80 & 2035.95 & $|5320.50|$ & 2040.80 & 0.81 & 0.24 \\
\hline & 5 & 30 & 4706.66 & 2354.19 & |4704.44 & 2352.86 & 0.05 & 0.06 \\
\hline & 6 & 40 & 7205.89 & 2098.28 & 7202.51 & 2093.43 & 0.05 & 0.23 \\
\hline & 7 & 45 & 3657.60 & 1172.06 & 3659.42 & 1171.10 & 0.05 & 0.08 \\
\hline & 8 & 50 & 3574.92 & 918.80 & 3572.49 & 916.22 & 0.07 & 0.28 \\
\hline \multirow{3}{*}{ 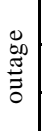 } & 1 & 0 & 6837.07 & 1967.63 & 6880.69 & 1965.90 & 0.64 & 0.09 \\
\hline & 2 & 10 & 6192.95 & 4326.77 & 6191.82 & 4328.41 & 0.02 & 0.04 \\
\hline & 8 & 50 & 7246.88 & 4033.86 & 7152.03 & 4027.89 & 1.32 & 0.15 \\
\hline
\end{tabular}

Fig. 10. Comparative table of maximum of mean of power supply for installations.

Through these comparisons we have proven that the new simulator performs as well as ESMERALDA and is suitable for study. This new simulator provides different numerical methods to solve the non linear circuit problem involved at each step of time and evolutivity capabilities to simulate tomorrow's railway networks.

\section{CONCLUSION}

A new methodology for generic formulation of railway electrical simulation problems has been proposed, based on an original meta-model of the network's components. The use of this meta-model makes the simulator expandable to new components, whose models are not known yet. The methods developed around this meta-model allow to explicitly formulate the non-linear circuit problem to be solved. Its use has been tested in the case of direct-current electrification systems. Dissociating the explicit formulation of the problem allowed us to compare and select the most effective solving algorithms. A comparison with a standard simulator has also been performed, so as to validate the new simulator. The creation of a component library for alternating-current electrification systems using the meta-model is currently being studied in order to confirm the genericity of the proposed method. Furthermore, this methodology will also be integrated into a rail simulation software platform in order to handle larger problems related to optimization of the power supply network.

\section{References}

[1] Mao Baohua, Jia Wenzheng, Chen Shaokuan, Liu Jianfeg, "Computeraided multi-train simulator for rail traffic," IEEE Vehicular Electronics and Safety, 13-15 December 2007.

[2] T.K. Ho, B.H. Mao, Z.Z. Yuan, H.D. Liu, Y.F. Fung, "Computer simulation and modeling in railway applications," Computer Physics Communications 143, 2002.

[3] Chang Han Bae, "A simulation study of installation locations and capacity of regeneratuve absorption in DC $1500 \mathrm{~V}$ electric railways system," Simulation Modelling Pratice and Theory 17, 2009, pp. 829838.

[4] A. Finlayson, C.J. Goodman, R.D. White, "Investigation into the computational techniques of power system modelling for a DC railway," Computers in railways X, WIT Transactions on The built Environment, Vol 88, 2006.

[5] A.L Allègre, A. Bouscayrol, P. Delarue, P. Barrade, E. Chattot and S. El-Fassi, "Energy storage system with supercacitor for an innovative subway," IEEE Transactions on Industrial electronics, vol. 57, no. 12, December 2010

[6] C.J. Goodman, L.K. Siu, T.K. Ho "A review of simulation models for railway systems," International Conference on Developments in Mass Transit Systems, 20-23 April 1988.

[7] Bharat Bhargava, "Railway electrification systems and configurations," Power Engineering Society Summer Meeting, 18-22 July 1999.

[8] M. Coto, P. Arboleya, C. Gonzales-Moran, "Optimization approach to unified AC/DC power flow applied to traction systems with catenary voltage constraints," Electrical Power and Energy Systems 53, 2013, pp. 434-441.

[9] Pablo Arboleya, Guzman Diaz, Manuel Coto, "Unified AC/DC power flow traction systems : a new concept," IEEE Transactions on vehicular technology, vol. 61, no. 6, July 2012

[10] Chung-Wen Ho, Albert E. Ruehli, Pierce A. Brennank, "The modified nodal approach to network analysis," IEEE Transactions on circuits and systems, vol cas-22, no. 6, June 1975.

[11] Satish Balay, G. William Gropp, Lois Curfman McInnes, Barry F. Smith, "PETSc the portable extensible toolkit for scientific computation," Argonne National Laboratory, 3.4.2, April 5, 1997 ed.

[12] N. Hadda, C. Catoire, E. Sourdille, M. Cucchiaro, "Integrated solutions for calculus of electromagnetic perturbation of railway track with real traffic conditions," $9^{\text {th }}$ World Congress on Railway Research, May 22 26, 2011. 